\title{
molecules
}

ISSN 1420-3049

Article

www.mdpi.com/journal/molecules

\section{Ultrasonication-Assisted Solvent Extraction of Quercetin Glycosides from 'Idared' Apple Peels}

\section{H. P. Vasantha Rupasinghe *, Priya Kathirvel and Gwendolyn M. Huber}

Tree Fruit Bio-product Research Program, Department of Environmental Sciences, Nova Scotia Agricultural College, P.O. Box 550, Truro, Nova Scotia, B2N 5E3, Canada

* Author to whom correspondence should be addressed; E-Mail: vrupasinghe@nsac.ca; Tel: +1-902-893-6623; Fax: +1-902-893-1404.

Received: 14 November 2011; in revised form: 22 November 2011 / Accepted: 22 November 2011 / Published: 25 November 2011

\begin{abstract}
Quercetin and quercetin glycosides are physiologically active flavonol molecules that have been attributed numerous health benefits. Recovery of such molecules from plant matrices depends on a variety of factors including polarity of the extraction solvent. Among the solvents of a wide range of dielectric constants, methanol recovered the most quercetin and its glycosides from dehydrated 'Idared' apple peels. When ultrasonication was employed to facilitate the extraction, exposure of $15 \mathrm{~min}$ of ultrasound wavelengths of dehydrated apple peel powder in $80 \%$ to $100 \%(\mathrm{v} / \mathrm{v})$ methanol in 1:50 (w:v) solid to solvent ratio provided the optimum extraction conditions for quercetin and its glycosides. Acidification of extraction solvent with $0.1 \%(\mathrm{v} / \mathrm{v})$ or higher concentrations of $\mathrm{HCl}$ led to hydrolysis of naturally occurring quercetin glycosides into the aglycone as an extraction artifact.
\end{abstract}

Keywords: flavonols; extraction; ultrasonication; quercetin; quercetin glycoside; acidification; apple

\section{Introduction}

Dietary plant polyphenolic molecules, specifically flavonoids, have become of a great interest due to their widely reported potential health benefits [1-4]. Quercetin is one of the most studied plant flavonoids and has been reported to have antioxidant, anticarcinogenic, antiinflammatory, antiaggregatory, antihypertensive and neuroprotective effects [5-8]. Quercetin glycosides have also 
been reported to be the most common flavonol in diet due to their presence in frequently consumed foods such as apples, onions and tea [5,9].

In plant tissues, flavonoids, including quercetin, are usually found in conjugated forms with sugars such as glucose, galactose and rhamnose [9-11]. These glycosylated quercetins are differentially distributed in the fruit tissue. For example, quercetin glycosides are found almost exclusively in the peel of apples $[9,12-14]$. There are a number of factors that influence flavonoid extraction from the plant matrix such as chemical nature of extraction solvent, sample to solvent ratio, sample particle size, disruption techniques, temperature as well as time of exposure [15]. Various methods for the extraction and quantification of phenolic molecules from apples have been reported [9,14-18].

In the past few years, there has been an increasing use of ultrasonication as a method to facilitate and accelerate extraction of phenolics from plant matrices [19]. This technique is particularly effective compared to other conventional extraction methods because it allows the disruption of cell compartments facilitating the interaction of phenolic molecules with solvents at reasonably low temperatures [20]. Moreover, other advantages include, drastically reduced processing time; consumption of less energy; increased recovery; and reduced thermal degradation effects [21].

The literature reveals that there is no extraction procedure that is universally suitable for structurally diverse phenolic molecules due to their differing chemical properties such as solubility, degree of polymerization and interaction with other components of the plant matrix [15]. This warrants standardizing extraction procedures for specific sub-classes of phenolic molecules of interest. Apple peels, one of the major dietary source for flavonols, i.e., quercetins [9,22], are also a by-product of apple processing industry $[23,24]$. Previous research also indicates strong radical scavenging and antioxidative protection property of polyunsaturated fatty acid oxidation of polyphenolic extracts of apple peels $[24,25]$. Hence, investigation of the optimization of extraction procedures for recovery of quercetin and its major glycosides from apple peels is useful. The purpose of this research was to compare the efficiency of solvents of varying polarities for the extraction of quercetin and its glycosides from dehydrated apple peel powder and then to optimize the extraction of flavonols using a selected solvent under ultrasonication-assisted extraction procedure. The effect of acidifying the extraction solvent was also examined.

\section{Results}

\subsection{Effect of Extraction Solvents of Varying Polarity}

The efficacy of solvents in flavonol extraction followed the order: Methanol $>$ acetone $>$ ethyl acetate (Table 1). Highly polar (water) and non-polar (chloroform) solvents were not effective in extracting flavonols from apple peels. Methanol was chosen for further studies as it provided the highest recovery of flavonols. 
Table 1. Effect of extraction solvents of varying polarity on the recovery of selected flavonols from dehydrated apple peels ${ }^{a}$.

\begin{tabular}{ccccccc}
\hline & \multicolumn{7}{c}{ Flavonols (mg/100 g DW) } \\
\cline { 2 - 7 } Solvent & $\begin{array}{c}\text { Dielectric } \\
\text { Constant }\end{array}$ & Quercetin & $\begin{array}{c}\text { Quercetin-3- } \\
\text { O-galactoside }\end{array}$ & $\begin{array}{c}\text { Quercetin-3- } \\
\text { O-rhamnoside }\end{array}$ & $\begin{array}{c}\text { Quercetin-3- } \\
\text { O-rutinoside }\end{array}$ & $\begin{array}{c}\text { Total } \\
\text { Quercetin \& } \\
\text { Glycosides }\end{array}$ \\
\hline Water & 80 & ND & ND & ND & ND & ND \\
Methanol & 33 & $1.3^{\mathrm{a}}$ & $64.6^{\mathrm{a}}$ & $26.5^{\mathrm{a}}$ & $2.2^{\mathrm{a}}$ & $94.6^{\mathrm{a}}$ \\
Acetone & 20.07 & $0.9^{\mathrm{a}}$ & $57.5^{\mathrm{b}}$ & $19.9^{\mathrm{b}}$ & $1.0^{\mathrm{a}}$ & $79.3^{\mathrm{b}}$ \\
E. acetate & 6.02 & $\mathrm{ND}$ & $12.3^{\mathrm{c}}$ & $8.8^{\mathrm{c}}$ & $\mathrm{ND}$ & $21.1^{\mathrm{c}}$ \\
Chloroform & 4.72 & $\mathrm{ND}$ & $\mathrm{ND}$ & $\mathrm{ND}$ & $\mathrm{ND}$ & ND \\
\hline
\end{tabular}

ND-Not detected. ${ }^{a}$ Means followed by the same letter within each row are not significantly different [Tukey's Studentized range test $(\mathrm{P}<0.05)$ ].

\subsection{Effect of Different Concentrations of Methanol and Extraction Time}

The response surface plots for the flavonols reflect the interaction effects (methanol $\times$ extraction time) through visible curvatures (Figure 1). The interaction between methanol concentration and time in the ultrasonic bath was significant for quercetin, quercetin-3-O-galactoside and quercetin-3-Orhamnoside $(\mathrm{p}<0.05)$. The interaction as well as the main effects was not found to be significant for quercetin-3-O-rutinoside, which could be due to the very low concentrations of this molecule recovered from apple peels.

The response surface curves for quercetin-3-O-galactoside and quercetin-3-O-rhamnoside, were very similar in shape (Figure 1). Both graphs showed a sharp increase in the recovery of the molecules from $60 \%$ to $70 \%$ methanol, then a slower increase from $80 \%$ to $100 \%$ aqueous methanol, for all time periods. However, the shape of the quercetin response curve is different from the glycosides, in that the recovery of the aglycone showed a more consistent increase from $60 \%$ to $100 \%$ methanol. An analysis of variance, blocked by flavonol, was performed to determine if the recovery of flavonols differed among the extraction solvents of aqueous methanol at $15 \mathrm{~min}$. The Tukey's mean comparison revealed that there was no significant difference in concentration of flavonols extracted using $80 \% v s .100 \%$ methanol as well as $70 \%$ vs. $80 \%$ methanol; however, $60 \%$ methanol extracted the lowest concentration of flavonols. In terms of sonication time, there was a general decrease in molecule recovery from $15 \mathrm{~min}$ to $75 \mathrm{~min}$ and an analysis of variance with Tukey's means comparison revealed a steady decline in extracted flavonols with $100 \%$ methanol after 15 min of ultrasonication $(p=0.0001)$.

\subsection{Effect of Acidification of Methanol Using Hydrochloric Acid}

The recovery of the selected flavonols in response to acidification of methanol ranged from 41.3 to $97.4 \mathrm{mg}$ per $100 \mathrm{~g} \mathrm{DW}$ (Table 2). The recovery of the molecules showed an interesting trend such that increasing concentration of $\mathrm{HCl}$ was associated with increasing concentration of quercetin aglycone and a decrease in the galactoside and rhamnoside concentrations (Table 2). Furthermore, a significantly lower concentration of quercetin and glycosides were obtained at higher levels of acidification (1.0 and $2.0 \% \mathrm{HCl}$ in methanol). 
Figure 1. Response surface plots indicating the extraction of flavonols (mg/100 g DW) using various concentrations of methanol (\%) at different ultrasonic bath times (min).
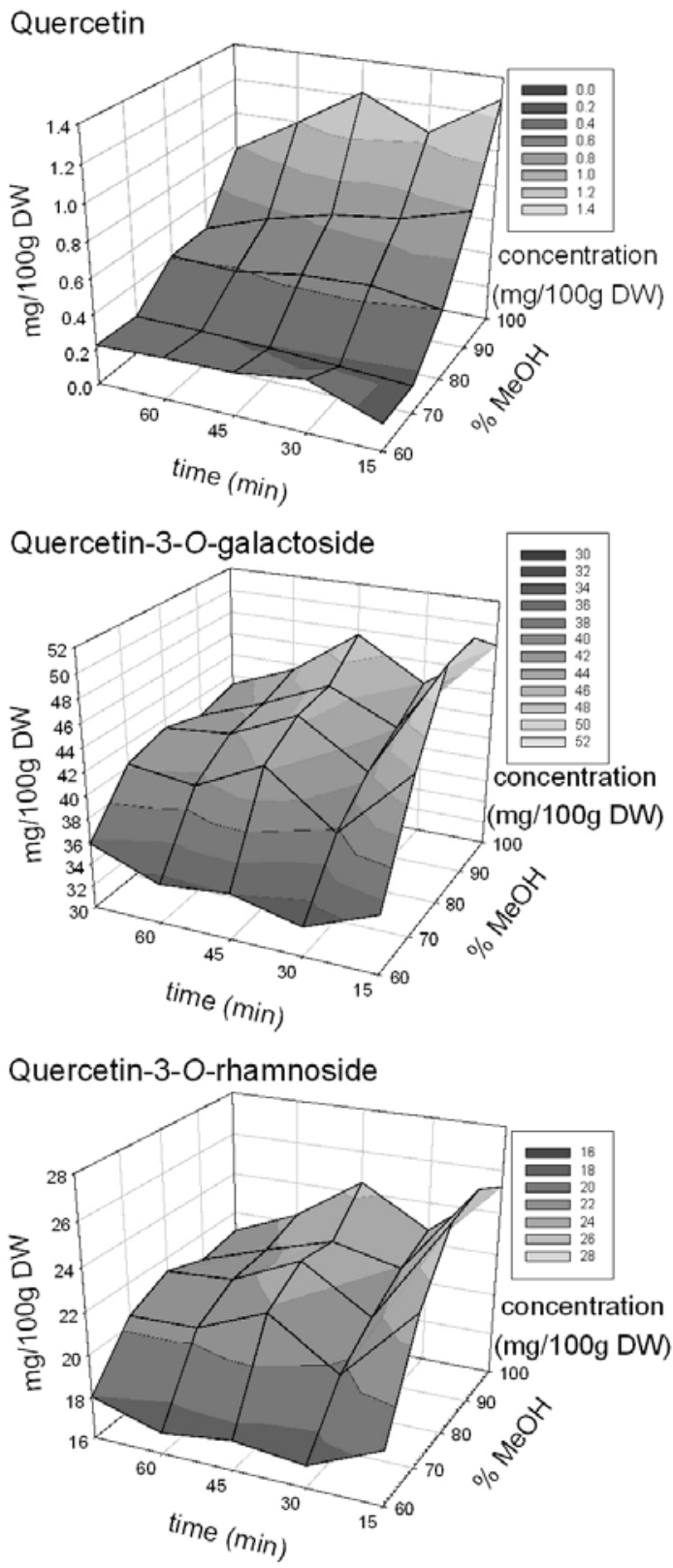

Table 2. Distribution of quercetin and selected quercetin glycosides in apple peel extracted with methanol containing various concentrations of hydrochloric acid ${ }^{a}$.

\begin{tabular}{lccccc}
\hline $\begin{array}{l}\text { \% HCl in } \\
\text { Methanol }\end{array}$ & $\begin{array}{c}\text { Quercetin } \\
(\mathbf{m g} / \mathbf{1 0 0} \mathbf{~ g W})\end{array}$ & $\begin{array}{c}\text { Quercetin-3-O- } \\
\text { galactoside } \\
(\mathbf{m g} / \mathbf{1 0 0} \mathbf{g ~ D W})\end{array}$ & $\begin{array}{c}\text { Quercetin-3-O- } \\
\text { rhamnoside } \\
(\mathbf{m g} / \mathbf{1 0 0} \mathbf{g ~ D W})\end{array}$ & $\begin{array}{c}\text { Quercetin-3-O- } \\
\text { rutinoside } \\
(\mathbf{m g} / \mathbf{1 0 0} \mathbf{g ~ D W})\end{array}$ & $\begin{array}{c}\text { Total quercetin } \\
\text { and glycosides } \\
(\mathbf{m g} / \mathbf{1 0 0} \mathbf{~ D W})\end{array}$ \\
\hline 0 & $1.48^{\mathrm{c}}$ & $63.5^{\mathrm{a}}$ & $23.8^{\mathrm{a}}$ & $1.35^{\mathrm{a}}$ & $90.1^{\mathrm{ab}}$ \\
0.01 & $1.43^{\mathrm{c}}$ & $61.9^{\mathrm{a}}$ & $23.6^{\mathrm{a}}$ & $1.18^{\mathrm{ab}}$ & $88.1^{\mathrm{b}}$ \\
0.1 & $24.7^{\mathrm{b}}$ & $55.4^{\mathrm{b}}$ & $15.9^{\mathrm{b}}$ & $1.49^{\mathrm{ab}}$ & $97.4^{\mathrm{a}}$ \\
1.0 & $36.3^{\mathrm{a}}$ & $12.4^{\mathrm{c}}$ & $0.51^{\mathrm{c}}$ & $1.15^{\mathrm{ab}}$ & $50.4^{\mathrm{c}}$ \\
2.0 & $34.4^{\mathrm{a}}$ & $5.48^{\mathrm{d}}$ & $0.58^{\mathrm{c}}$ & $0.89^{\mathrm{b}}$ & $41.3^{\mathrm{c}}$ \\
\hline
\end{tabular}

${ }^{a}$ Means followed by the same letter within each row are not significantly different [Tukey's Studentized range test $(\mathrm{P}<0.05)]$. 


\section{Discussion}

Understanding the distribution and concentration of bioactive flavonol molecules in dietary sources is important for both fundamental researches in natural product chemistry as well as development of natural health products. Discrepancies in the reported concentrations of flavonols from the dietary sources could be due to a variety of factors. However, standardization of extraction procedures for specific phenolic sub-classes is one of the important requirements. Currently, most of the reported phenolic extraction procedures from plant sources are arbitrarily selected methods without optimization for specific molecules of interest. As well, one extraction method has been commonly used for quantification of many sub-classes of phenolics due to the convenience. This study was an attempt to optimize the recovery of selected flavonols, quercetin and its glycosides, from dehydrated and ground 'Idared' apple peels using an extraction procedure based on methanol and ultrasonication.

A comparative study of extraction solvents of varying polarity revealed that methanol was effective in extracting quercetin and quercetin glycosides from dehydrated 'Idared' apple peels when ultrasonication was used to facilitate the extraction. Response surface plots indicated that $80 \%$ to $100 \%$ methanol and ultrasonication duration of $15 \mathrm{~min}$ was the most effective combination for extracting quercetin and its glycosides from de-hydrated apple peel. Increased recovery of flavonols with higher concentrations of methanol could be attributed to the relatively non-polar nature of the flavonol molecules examined [15]. The decrease in the recovery of quercetin, quercetin-3-O-galactoside, and quercetin-3-O-rhamnoside over time could be due to the hydrolysis of glycosides and degradation of the aglycone due to extended extraction period. The temperature of ultrasonic bath was maintained below $30{ }^{\circ} \mathrm{C}$ though the quercetin has been shown to be relatively stable during various cooking processes except blanching [26].

Acidification of solvent is commonly practice when all sub-classes of phenolics are co-extracted with the aim of stabilizing anthocyanins [15]. When $\mathrm{HCl}$ was added to the methanol for extraction of flavonol from 'Idared' apple peel, it was observed that the increasing concentration of $\mathrm{HCl}$ is directly proportional to the recovery of quercetin, but inversely proportional to the recovery of quercetin glycosides. The observation suggests that when $0.1 \%(\mathrm{v} / \mathrm{v})$ or higher concentrations of $\mathrm{HCl}$ incorporated in extraction solvent, glycosides release the aglycone quercetin due to hydrolysis. Therefore, in the presence of $\mathrm{HCl}$ in the extraction solvent, over estimation of quercetin in tested plant materials can be occurred. Furthermore, when $\mathrm{HCl}$ was incorporated at $1 \%$ and $2 \%$, the total concentration of quercetin and glycosides were significantly decreased. This suggests that degradation of quercetin could occur under these conditions and the newly formed products need to be identified. Since most flavonols occur naturally in the glycosylated form, the acidification of solvents is not appropriate in terms of determining the distribution and concentration of naturally occurring flavonols in plant tissues. Quercetin galactoside was the most abundant flavonol in dehydrated apple peels when extraction was carried without acidification of methanol. Quercetin rhamnoside and quercetin rutinoside were the two other major flavonols identified. This is in agreement with previous studies by $[9,12,23,24]$. 


\section{Experimental}

\subsection{Materials and Chemicals}

'Idared' apple peels were collected from a commercial apple pie processing manufacturer (Apple Valley Foods Inc., Kentville, NS, Canada). HPLC-grade methanol, acetonitrile and formic acid were purchased from Sigma-Aldrich (St. Louis, MO, USA). The liquid chromatography standards used for the study were obtained as follows: Quercetin-3-O-rhamnoside and quercetin-3-O-galactoside were from Indofine Chemical Company (Hillsborough, NJ, USA); quercetin was from Sigma-Aldrich (St. Louis, MO, USA); and quercetin-3-O-rutinoside was from ChromaDex (Santa Ana, CA, USA). Other solvents were obtained from Fisher Scientific (Ottawa, ON, Canada).

\subsection{Sample Preparation and Flavonol Extraction}

The apple peels were processed into a dry powder using a previously described procedure [23]. For the extraction of flavonol molecules using different solvents, dehydrated apple peel $(0.5 \mathrm{~g})$ was mixed with solvent $(25 \mathrm{~mL})$ in glass stoppered Erlenmeyer flasks $(125 \mathrm{~mL}$ capacity). In the subsequent study, two extraction factors were examined: percentage aqueous methanol as the extraction solvent and the duration in the ultrasonic bath. For each treatment, the extraction solvent $(50 \mathrm{~mL})$ was used to extract the phenolic molecules from dehydrated apple peel $(1 \mathrm{~g})$ using glass stoppered Erlenmeyer flasks $(125 \mathrm{~mL}$ capacity). In another study, several levels of acidification of methanol were examined for quercetin and quercetin glycoside extraction from dehydrated apple peel powder $(1 \mathrm{~g})$. The extraction solvent used in this experiment was $50 \mathrm{~mL}$ of methanol containing $0 \%, 0.01 \%, 0.1 \%, 1 \%$ and $2 \%(\mathrm{v} / \mathrm{v}) \mathrm{HCl}$.

For the comparison of various solvents, $100 \%$ water, methanol, acetone, ethyl acetate and chloroform were used and the apple peel powder-solvent mixture was vortexed well, placed in the ultrasonic bath of $20 \mathrm{kHz} / 1000$ Watts (model 750D, VWR, West Chester, PA, USA) and exposed for $60 \mathrm{~min}$ (four times for $15 \mathrm{~min}$ each with $10 \mathrm{~min}$ interval in between). The temperature of the ultrasonic bath was between 20 to $28{ }^{\circ} \mathrm{C}$. Three replicates of each solvent were prepared. In the second study, the levels of methanol used were $60 \%, 70 \%, 80 \%, 90 \%$ and $100 \%(\mathrm{v} / \mathrm{v})$. Three replicates of each methanol concentration were prepared using deionized water. The apple peel powder and the extraction solvent were vortexed and the flasks were placed in the ultrasonic bath for $15 \mathrm{~min}$ intervals up to $75 \mathrm{~min}$, with $10 \mathrm{~min}$ breaks for sampling. Samplings consisted of removing $400 \mu \mathrm{L}$ of the solution, which was filtered (nylon 0.45 micron filters, Waters Co., Milford, MA, USA) before being placed into HPLC auto-sample vials with inserts for the liquid chromatography, tandem mass spectrometry (HPLC-MS/MS) analysis [23,24]. Only exception to this procedure was when acetone, ethyl acetate and chloroform were used as the solvent, $400 \mu \mathrm{L}$ of the extract was taken in small test tubes $(12 \times 75 \mathrm{~mm})$ and evaporated under nitrogen followed by re-dissolving in 100\% methanol before used for HPLC-MS/MS analysis. For the acidification experiment, ultrasonication was carried out for $15 \mathrm{~min}$.

\subsection{Liquid Chromatography and Mass Spectrometry Analysis}

The HPLC system consisted of a Waters Alliance 2695 Separations Module and the column used was a Phenomenex Luna C18 $(150 \mathrm{~mm} \times 2.1 \mathrm{~mm}, 5 \mu \mathrm{m})$ with a Waters X-Terra MS C18 guard 
column. Gradient elution was carried out with $0.1 \%$ formic acid in water (Solvent A) and $0.1 \%$ formic acid in acetonitrile (Solvent B) at a flow rate of $0.35 \mathrm{~mL} / \mathrm{min}$. A linear gradient profile was used with the following proportions of Solvent A applied at time $t(\mathrm{~min}) ;(\mathrm{t}, \mathrm{A} \%)$ : $(0,94 \%),(9,83.5 \%),(11.5$, $83 \%),(14,82.5 \%),(16,82.5 \%),(18,81.5 \%),(21,80 \%),(29,0 \%),(31,94 \%),(40,94 \%) . \mathrm{MS} / \mathrm{MS}$ experiments were preformed on a Waters Micromass Quattro micro API triple quadrupole mass spectrometer controlled by the Masslynx V4.0 data analysis system (Micromass, Cary, CA, USA). Electrospray ionization in negative ion mode (ESI-) was used for the analysis of the quercetin molecules. In negative mode, the following tune settings were used: capillary voltage 3,000 V, nebulizer gas temperature $\left(\mathrm{N}_{2}\right) 375^{\circ} \mathrm{C}$ at a flow rate of $600 \mathrm{~L} / \mathrm{h}$. The MS settings were tuned for each individual molecule. Analytes were identified and quantified using multiple reactions monitoring (MRM) mode in comparison with standards (Table 3). In the MS/MS experiments, both quadrupoles were operated at unit resolution.

Table 3. Retention times and ion transitions for flavonols quantified in apple peel powder using HPLC-MS/MS using multiple reactions monitoring (MRM) mode.

\begin{tabular}{lll}
\hline Flavonol molecule & Retention Time $(\mathbf{m i n})$ & Ion Transition $(\mathbf{m} / \boldsymbol{z})$ \\
\hline quercetin-3- $O$-rutinoside & 16.36 & $609 \rightarrow 301$ \\
quercetin-3- $O$-galactoside & 17.51 & $464 \rightarrow 301$ \\
quercetin-3- $O$-rhamnoside & 23.00 & $448 \rightarrow 301$ \\
quercetin & 27.16 & $301 \rightarrow 151$ \\
\hline
\end{tabular}

\subsection{Experimental Design and Statistical Analysis}

The statistical design of the experiment examining the effect of methanol concentration and extraction time was a two factor factorial design with the response as mg per $100 \mathrm{~g}$ dry weight (DW) of each flavonol. After ensuring normality and constant variance of the data using the AndersonDarling test and an examination of the residuals versus fits plot, a two-way analysis of variance was used to check for significance at $\alpha=0.05$ using SAS 9.1 (SAS Institute, San Jose, CA, USA). As well, response surface curves for the extraction of the selected flavonols were created using Sigma Plot 8.0 (Systat Software, Richmond, CA, USA). The solvent comparison experiment and the acidification experiment used a completely randomized design with three replicates respectively to examine the difference in recovery of the quercetin molecules. The recovery of flavonols was compared using an analysis of variance with Tukey's means comparison using SAS 9.1.

\section{Conclusions}

This study reveals that $80 \%$ to $100 \%$ methanol combined with exposure to 15 min ultrasonication could serve as an efficient method for the extraction of flavonols from 'Idared' apple peels. Even though this work is focused on only one apple cultivar, it is highly possible that the same extraction procedure could be adopted for the recovery of flavonols from the peels of other apple cultivars and similar plant matrices. Further studies on the influence of other critical variables such as sample to solvent ratio, particle size etc on the efficiency of flavonol extraction process from apple peels might be useful for scale-up extractions of flavonol molecules. 


\section{Acknowledgements}

This research was funded by the Natural Science and Engineering Research Council (NSERC) of Canada and the Atlantic Innovation Funds (AIF) program of the Atlantic Canada Opportunities Agency (ACOA).

\section{References and Notes}

1. Hollman, P.C.; Katan, M.B. Absorption, metabolism and health effects of dietary flavonoids in man. Biomed. Pharmacother. 1997, 51, 305-310.

2. Hertog, M.G.; Kromhout, D.; Aravanis, C. Flavonoid intake and long-term risk of coronary heart disease and cancer in the seven countries study. Arch. Int. Med. 1995, 155, 381-386.

3. Zhao M.; Yang B.; Wang J.; Liu Y.; Yu L.; Jiang Y.M. Immuno modulatory and anticancer activities of flavonoids extracted from litchi (Litchi chinensis Sonn) pericarp. Int. Immunopharmacol. 2007, 7, 162-166.

4. Xiao, Z.-P.; Peng, Z.-Y.; Pen, M.-J.; Yan, W.-B.; Ouyang, Y.-Z.; Zhu, H.L. Flavonoids health benefits and their molecular mechanism. Mini-Rev. Med. Chem. 2011, 11, 169-177.

5. Erlund, I. Review of the flavonoids quercetin, hesperetin, and naringenin. Dietary sources, bioactivities, bioavailability, and epidemiology. Nutr. Res. 2004, 24, 851-874.

6. Soundararajan, R.; Wishart, A.D.; Rupasinghe, H.P.V.; Arcellana-Panlilio, M.; Nelson, C.M.; Mayne, M.; Robertson, G.S. Quercetin 3-glucoside protects neuroblastoma (SH-SY5Y) cells in vitro against oxidative damage by inducing sterol regulatory element-binding protein-2-mediated cholesterol biosynthesis. J. Biol. Chem. 2008, 283, 2231-2245.

7. Jan, A.T.; Kamli, M.R.; Murtaza, I.; Singh, J.B.; Ali, A.; Haq, Q.M.R. Dietary flavonoid quercetin and associated health benefits - An overview. Food Rev. Int. 2010, 26, 302-317.

8. Balasuriya, B.W.N.; Rupasinghe, H.P.V. Plant flavonoids as angiotensin converting enzyme inhibitors in regulation of hypertension. Funct. Foods Health Dis. 2011, 5, 172-188.

9. Huber, G.M.; Rupasinghe, H.P.V. Phenolic profiles and antioxidant properties of apple skin extracts. J. Food Sci. 2009, 74, 693-700.

10. Schieber, A.; Hilt, P.; Conrad, J.; Beifuss, U.; Carle, R. Elution order of quercetin glycosides from apple pomace extracts on a new HPLC stationary phase with hydrophilic end-capping. J. Sep. Sci. 2002, 25, 361-364.

11. Herrera, M.; Luque de Castro, M. Ultrasound-assisted extraction for the analysis of phenolic compounds in strawberries. Anal. Bioanal. Chem. 2004, 379, 1106-1112.

12. Tsao, R.; Yang, R.; Young, C.; Zhu, H. Polyphenolic profiles in eight apple cultivars using high-performance liquid chromatography (HPLC). J. Agric. Food Chem. 2003, 51, 6347-6353.

13. Chinnici, F.; Gaiani, A.; Natali, N.; Riponi, C.; Galassi, S. Improved HPLC determination of phenolic compounds in Cv. Golden Delicious apples using a monolithic column. J. Agric. Food Chem. 2004, 52, 3-7.

14. McGhie, T.; Hunt, M.; Barnett, L. Cultivar and growing region determine the antioxidant polyphenolic concentration and composition of apples grown in New Zealand. J. Agric. Food Chem. 2005, 53, 3065-3070. 
15. Naczk, M.; Shahidi, F. Extraction and analysis of phenolics in food. J. Chromat. A 2004, 1054, 95-111.

16. Lu, Y.; Foo, L.Y. Identification and quantification of major polyphenols in apple pomace. Food Chem. 1997, 59, 187-194.

17. Price, K.; Prosser, T.; Richetin, A.; Rhodes, M. A comparison of the flavonol content and composition in dessert, cooking and cider-making apple; distribution within the fruit and effect of juicing. Food Chem. 1999, 66, 489-494.

18. Reay, P.; Lancaster, J. Accumulation of anthocyanins and quercetin glycosides in 'Gala' and 'Royal Gala' apple fruit skin with UV-B-Visible irradiation: Modifying effects of fruit maturity, fruit scale, and temperature. Sci. Hort. 2001, 90, 57-68.

19. Kataoka, H. New trends in sample preparation for analysis of plant-derived medicines. Curr. Org. Chem. 2010, 14, 1698-1713.

20. Shi, J.; Nawaz, H.; Pohorly, J.; Mittal, G.; Kakuda, Y.; Jiang, Y. Extraction of polyphenolics from plant material for functional foods-Engineering and technology. Food Rev. Int. 2005, 21, 139-166.

21. Zenker, M.; Zenker, V.H.; Knorr, D. Application of ultrasound-assisted thermal processing for preservation and quality retention of liquid foods, J. Food Prot. 2003, 66, 1642-1649.

22. Rupasinghe, H.P.V.; Kean, C. Polyphenol concentrations in apple processing by-products deterined using electrospray ionization mass spectrometry. Can. J. Plant Sci. 2008, 88, 759-762.

23. Rupasinghe, H.P.V.; Wang, L.; Huber, G.M.; Pitts, N.L. Effect of baking on dietary fibre and phenolics of muffins incorporated with apple skin powder. Food Chem. 2009, 107, 1217-1224.

24. Rupasinghe, H.P.V.; Erkan, N.; Yasmin, A. Antioxidant protection of eicosapentaenoic acid and fish oil oxidation by polyphenolic-enriched apple skin extract. J. Agric. Food Chem. 2010, 58, 1233-1239.

25. Huber, G.M.; Rupasinghe, H.P.V.; Shahidi, F. Inhibition of oxidation of omega-3 polyunsaturated fatty acids and fish oil by quercetin glycosides. Food Chem. 2009, 117, 290-295.

26. Ewald, C.; Fjelkner-Modig, S.; Jahansson, K.; Sjoholm, I.; Akesson, B. Effect of processing on major flavonoids in processed onions, green beans, and peas. Food Chem. 1999, 64, 231-235.

Sample Availability: Quercetin-3-O-rhamnoside and quercetin-3-O-galactoside: Indofine Chemical Company (Hillsborough, NJ, USA); quercetin: Sigma-Aldrich (St. Louis, MO, USA); and quercetin-3$O$-rutinoside: ChromaDex (Santa Ana, CA, USA). Apple peel powder is available from the authors.

(C) 2011 by the authors; licensee MDPI, Basel, Switzerland. This article is an open access article distributed under the terms and conditions of the Creative Commons Attribution license (http://creativecommons.org/licenses/by/3.0/). 